\title{
PHAGOCYTOSIS AND MACROPHAGE POLARISATION ON BACTERIALLY CONTAMINATED DENTAL IMPLANT MATERIALS AND EFFECTS ON TISSUE INTEGRATION
}

\author{
Y. Yuan ${ }^{1,2}$, Y. Ren ${ }^{3}$, M. Dijk ${ }^{3}$, G.I. Geertsema-Doornbusch ${ }^{1}$, J. Atema-Smit ${ }^{1}$, H.J. Busscher ${ }^{1}$ \\ and H.C. van der Mei ${ }^{1, *}$ \\ ${ }^{1}$ University of Groningen and University Medical Centre Groningen, Department of Biomedical \\ Engineering, Antonius Deusinglaan 1, 9713 AV Groningen, the Netherlands \\ ${ }^{2}$ College of Chemistry, Chemical Engineering and Materials Science, Soochow University, 199 Ren'ai Rd, \\ Suzhou 215123, Jiangsu, P. R. China \\ ${ }^{3}$ University of Groningen and University Medical Centre of Groningen, Department of Orthodontics, \\ Hanzeplein 1, 9700 RB Groningen, the Netherlands
}

\begin{abstract}
Bacterial contamination is hard to avoid during dental implant surgery. Macrophages and their polarisation play a decisive role in bacterial colonisation and tissue integration on bacterially contaminated dental implants. The present study investigated the role of macrophages in stimulating tissue coverage overgrowth of contaminating oral bacteria on polished titanium (Ti-P) and acid-etched zirconium dioxide $\left(\mathrm{ZrO}_{2}-\mathrm{MA}\right)$ dental implant materials. Different co-culture models were employed to determine phagocytosis rates of Streptococcus mitis or Staphylococcus aureus contaminating a dental implant surface and the influence of contaminating bacteria and osteoblasts (U2OS) on macrophage polarisation. S. aureus was phagocytized in higher numbers than S. mitis in bi-cultures on smooth Ti-P surfaces. Contaminating S. mitis stimulated near full polarisation of macrophages from a non-Ym1-expressing- to a Ym1-expressing-phenotype on smooth Ti-P, but on $\mathrm{ZrO}_{2}-\mathrm{MA}$ both phenotypes occurred. In tri-cultures with U2OS-cells on smooth Ti-P, a larger percentage of macrophages remained in their non-Ym1-expressing, "fighting" M1-like phenotype to clear Ti-P surfaces from contaminating bacteria. On $\mathrm{ZrO}_{2}-\mathrm{MA}$ surfaces, more macrophages tended towards their "fixand-repair" M2-like phenotype than on Ti-P surfaces. Surface coverage of smooth, bacterially contaminated Ti-P surfaces by U2OS-cells was more effectively stimulated by fighting, M1-like macrophages than on $\mathrm{ZrO}_{2}-\mathrm{MA}$ surfaces. Comprehensive guidelines are provided for the development of infection-resistant, dental implant materials, including bacteria, tissue and immune cells. These guidelines point to more promising results for clinical application of Ti-P as compared with $\mathrm{ZrO}_{2}-\mathrm{MA}$.
\end{abstract}

Keywords: Titanium, zirconium, M1 phenotype, M2 phenotype, co-cultures, U2OS cells, YM1, bacterial adhesion.

*Address for correspondence: Henny C. van der Mei, Biomedical Engineering, University Medical Centre Groningen, Antonius Deusinglaan 1,9713 AV Groningen, the Netherlands.

Email: h.c.van.der.mei@umcg.nl

Copyright policy: This article is distributed in accordance with Creative Commons Attribution Licence (http://creativecommons.org/licenses/by-sa/4.0/).

\section{Introduction}

The use of biomaterials to restore or maintain function contributes greatly to a life-long, high quality of life. The number of biomaterial implants clinically applied is still growing with increasing life expectancy and advances in materials science. However, the presence of a biomaterial implant in the human body results in the danger of biomaterialassociated infection (Busscher et al., 2012). Currently, biomaterial-associated infections are the main cause of implant failure and have rapidly become a societal burden related to the high-costs of revision surgery, prolonged courses of antibiotic treatment and a compromised quality of life (Le et al., 2014). Biomaterial-associated infections arise in many cases from bacterial contamination of the implant or the implant site during surgery or immediately following surgery. In orthopaedic surgery, extreme precautions are taken to ensure sterile implantation of prosthetic hips and knees, yet infection rates are similar to those of dental implants that are placed 
in the inherently unsterile environment of the oral cavity. This paradox of implant infection (Yue et al., 2015) has been explained by a high tolerance of the local immune system in the oral cavity as compared with a hyperactive immune system elsewhere in the body.

In an innate immune response, macrophages - in their fighting M1-phenotype - are in the first instance prepared to fight the presence of a biomaterial or kill an invading pathogens. Killing of invading pathogens occurs following their internalisation by macrophages and uptake into phagolysosomes containing different proteases, reactive oxygen and nitrogen species as well as antimicrobial peptides that jointly facilitate pathogen killing (Leseigneur et al., 2020). However, macrophages may also respond by polarisation towards their M2-phenotype to fix-andrepair bacterial damage done to tissue cells (Miron and Bosshardt, 2016). Thus, regardless of whether in their M1- or M2-phenotype or in one of the numerous "in between" phenotypes (Mills and Ley, 2014), macrophages will play a decisive role in the race for an implant surface between bacterial colonisation and tissue integration (Busscher et al., 2012).

Earlier implant material evaluating studies have predominantly examined single factors, such as the interaction of a biomaterial surface with bacteria, osteoblasts, stem cells or host immune cells (Porter et al., 2018; Sapru et al., 2018). To better understand the interaction between key-players in an infection associated with implanted biomaterials, co-culture models comprising the biomaterial, bacteria, tissue cells and/or macrophages have been developed. Co-culture models have even been advocated as a bridge to clinical studies that might reduce the need for animal studies. This makes sense, particularly with respect to the oral cavity, because the huge difference between animal and human microflora lowers the relevance of animal studies. Co-culture studies can be carried out with human oral bacterial strains. Two types of co-culture studies can be distinguished: a peri- and post-operative mode, of which peri-operative bacterial contamination is most commonly used with tissue cells and bacteria competing for sites on bacterially-contaminated biomaterial surfaces (Subbiahdoss et al., 2011). Monoculture studies for instance, on a variety of ceramic $\left(\mathrm{ZrO}_{2}\right)$ or metal-based (Ti or TiZr) dental implant materials, have shown that diverse oral pathogens can form a biofilm on all biomaterials regardless of their physicochemical properties, while human gingival fibroblasts can equally cover $80-90 \%$ of these dental implant material surfaces (Zhao et al., 2014). Conversely, in bi-culture studies, human oral fibroblasts lost the race for the surface against many bacterial strains on nearly all implant materials, except the smoothest titanium variants, implying that such surfaces provide the best opportunities for a soft tissue seal to form on bacterially contaminated dental implants (Zhao et al., 2014). This conclusion coincided with results from the few large-scale clinical studies carried out to this end (Charalampakis et al., 2012). Evidently, mono-culture studies oversimplify the in vivo situation; therefore, in vitro results obtained from mono-culture studies bear little clinical relevance and could well be misleading.

In the search for metal-free dental implant materials, zirconia $\left(\mathrm{ZrO}_{2}\right)$ has emerged as a highly tissue-friendly ceramic for use in the abutment part of an implant, with superior aesthetics as compared with titanium abutments (Sivaraman et al., 2018). The race for the surface on these two frequently used abutment materials was studied. The role of macrophages and their polarisation in stimulating tissue coverage over the growth of contaminating oral bacteria, employing diverse mono-, bi- and tri-cultures, on polished titanium and zirconia dental implant materials was evaluated. Two oral bacterial strains were used: Streptococcus mitis, as a relatively harmless commensal of the oral cavity, and Staphylococcus aureus, an opportunistic oral pathogen found in early dental implant associated infection ("peri-implantitis") (Canullo et al., 2016; Mombelli and Décaillet, 2011).

\section{Materials and Methods}

\section{Implant materials}

In this study, metallic titanium (Ti) and ceramic zirconia $\left(\mathrm{ZrO}_{2}\right)$ were used as dental implant materials. Materials were provided by Institut Straumann AG (Basel, Switzerland) and received as discs (diameter $5 \mathrm{~mm}$, thickness $1 \mathrm{~mm}$ ). Surfaces were mirror polished (Ti-P) or ground and acid etched ( $\left.\mathrm{ZrO}_{2}-\mathrm{MA}\right)$ (Zhao et al., 2014). In Table 1, known surface properties of the Ti-P and $\mathrm{ZrO}_{2}-\mathrm{MA}$ samples relevant for bacterial adhesion and growth and tissue integration are summarised, including scanning electron micrographs. Most notably, $\mathrm{ZrO}_{2}-$ MA surfaces are morphologically rougher and more hydrophobic than Ti-P surfaces.

\section{Bacterial strains and culturing}

For contamination of the implant materials, S. mitis BMS, a member of the healthy oral microbiome (Aas et al., 2005) and S. aureus ATCC25923, an emerging dental implant-associated pathogen (Canullo et al., 2016), were used. Both strains have been used before in co-culture studies (Zhao et al., 2014) and results are in agreement with those from a large-scale clinical study (Charalampakis et al., 2012). This suggests that both strains are representative for the competition between contaminating bacteria and tissue cells on dental implant surfaces. Bacterial strains were streaked onto blood-agar plates and incubated for $24 \mathrm{~h}$ at $37^{\circ} \mathrm{C}$ and one colony was inoculated in $10 \mathrm{~mL}$ Todd Hewitt Broth (THB; OXOID, Basingstoke, UK) for S. mitis and Tryptone Soya Broth (TSB; OXOID) for $S$. aureus and grown for $24 \mathrm{~h}$ at $37^{\circ} \mathrm{C}$. After $24 \mathrm{~h}$, $200 \mathrm{~mL}$ of culture medium was inoculated with the preculture and grown for $16 \mathrm{~h}$ at $37^{\circ} \mathrm{C}$. Bacteria were 
Table 1. Physical-chemical properties of Ti-P and $\mathrm{ZrO}_{2}-\mathrm{MA}$ surfaces used in the study. Includes scanning electron micrographs (SEM, bar denotes $10 \mu \mathrm{m}$ ), surface roughness $\mathrm{R}_{\mathrm{a}^{\prime}}$, water contact angles $\theta_{w^{\prime}}$ elemental surface compositions in at \%. Data taken from (Zhao et al., 2014).

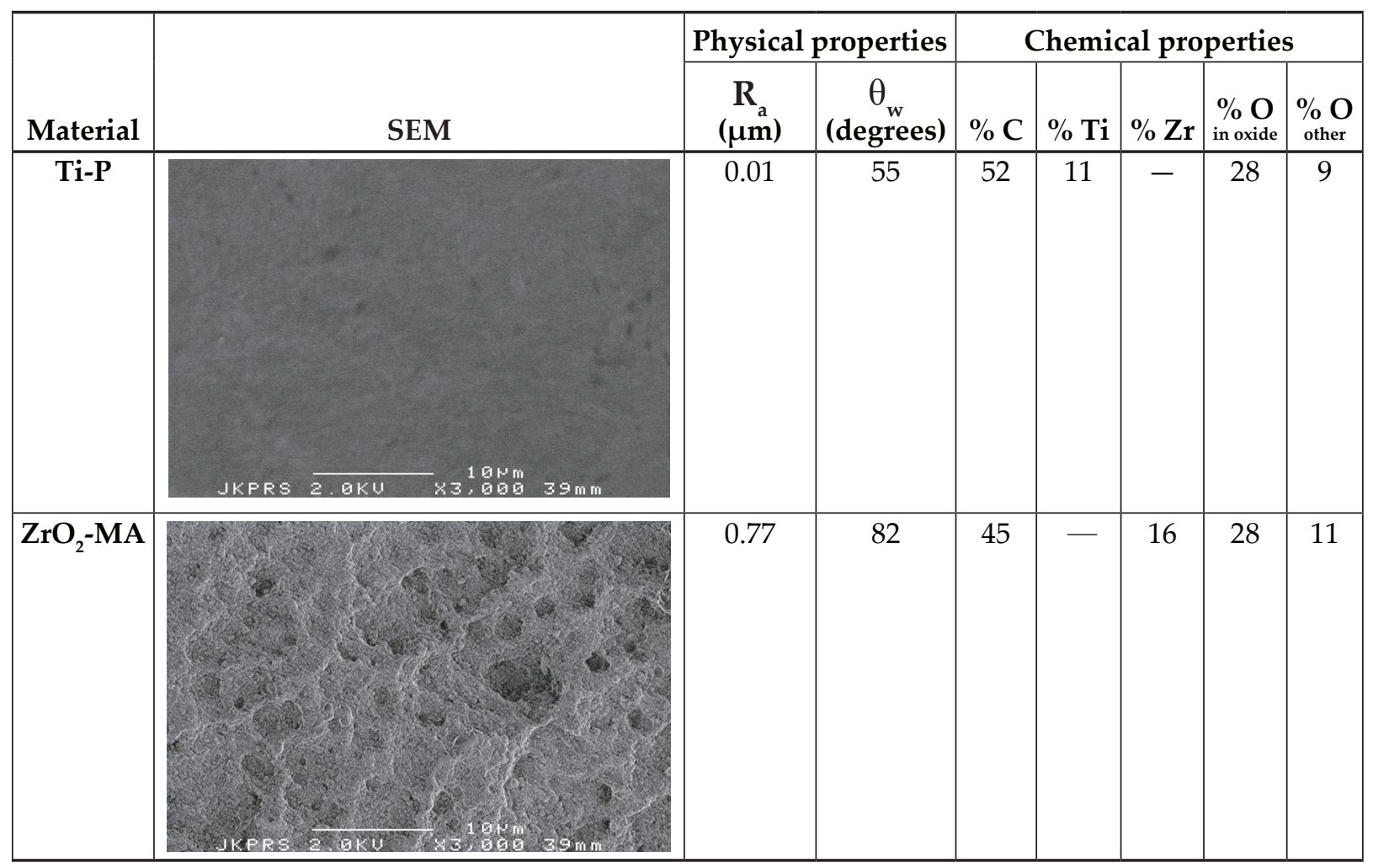

harvested by centrifugation at 5,000 $\times g$ for $5 \mathrm{~min}$ at $10{ }^{\circ} \mathrm{C}$, and $\mathrm{S}$. mitis was washed twice with sterile adhesion buffer $(2 \mathrm{mmol} / \mathrm{L}$ potassium phosphate, $50 \mathrm{mmol} / \mathrm{L}$ potassium chloride, and $1 \mathrm{mmol} / \mathrm{L}$ calcium chloride, $\mathrm{pH}$ 6.8), while $S$. aureus was washed with sterile phosphate buffered saline (PBS, $10 \mathrm{mmol} / \mathrm{L}$ potassium phosphate, $0.15 \mathrm{~mol} / \mathrm{L} \mathrm{NaCl}, \mathrm{pH}$ 7.0). Subsequently, bacteria were sonicated at $30 \mathrm{~W}$ (Vibra Cell model 375; Sonics and Materials, Danbury, CT, USA) on ice $(3 \times 10 \mathrm{~s})$ in sterile buffer to break bacterial chains and aggregates. Bacteria were counted in a Bürker-Türk counting chamber and diluted to a concentration of $3 \times 10^{8}$ bacteria/mL.

\section{Macrophages and culturing}

Murine macrophages (J774A.1; ATCC TIB-67; LGC Wesel, Germany) were cultured in tissue culture polystyrene flasks with Dulbecco's modified Eagle's medium-high glucose (DMEM-HG, $4.5 \mathrm{~g} / \mathrm{L}$ glucose) with $10 \%$ foetal calf serum (FBS) and $0.2 \mathrm{mmol} / \mathrm{L}$ ascorbic acid-2-phosphate (AA2P), denoted as DMEM-HG-complete, at $37{ }^{\circ} \mathrm{C}$ and $5 \% \mathrm{CO}_{2}$. At 80-90\% confluency, the macrophages were harvested by scraping and centrifugation at $600 \times g$ for $5 \mathrm{~min}$ and resuspended in DMEM-HGcomplete. The cells harvested were counted using a Sceptor ${ }^{\mathrm{TM}}$ handheld automated cell counter (Merck, Germany) and diluted to a concentration of $6 \times 10^{5}$ macrophages/mL for experiments under flow and $4 \times 10^{4} / \mathrm{mL}$ for experiments under static conditions. For bi- and tri-culture experiments, the macrophages were suspended in modified culture medium (see section below) in order to grow bacteria and cells simultaneously in the same culture medium.

\section{Osteoblasts and culturing}

U2OS osteoblasts (ATCC HTB-94) were cultured in Dulbecco's modified Eagle's medium low glucose (DMEM-LG) supplemented with $10 \%$ FBS and $0.2 \mathrm{mmol} / \mathrm{L}$ AA2P, denoted as DMEM-LG-complete. Cells were grown at $37{ }^{\circ} \mathrm{C}$ in $5 \% \mathrm{CO}_{2}$. Cells were passaged and harvested at $80-90 \%$ confluency using trypsin/EDTA and harvested by centrifugation at $600 \times g$ for $5 \mathrm{~min}$ and resuspended in DMEM-LGcomplete. The cells harvested were counted using the Sceptor ${ }^{\mathrm{TM}}$ handheld automated cell counter and diluted to $2 \times 10^{4} / \mathrm{mL}$ in modified culture medium for static mono-, bi- and tri-culture experiments.

\section{Modified culture medium for bi-culturing and tri-culturing}

$\mathrm{Bi}-$ and tri-culture experiments necessitated the development of a suitable co-culture medium in which osteoblasts, macrophages and/or bacteria could grow together (Subbiahdoss et al., 2009). To this end, bacterial culture medium (THB or TSB for S. mitis or $S$. aureus, respectively) and tissue culture medium DMEM-HG-complete were combined in different ratios and growth rates of bacteria, osteoblasts or macrophages were determined separately. For bacteria, precultures were grown in $10 \mathrm{~mL}$ THB or TSB for $24 \mathrm{~h}$, from which $0.5 \mathrm{~mL}$ was used to inoculate $9.5 \mathrm{~mL}$ of a co-culture medium for $16 \mathrm{~h}$. After $16 \mathrm{~h}$, bacteria were counted using a Bürker-Türk (Novolab 
B.V., Belgium) counting chamber. Also, macrophages and osteoblasts $\left(2 \times 10^{5}\right.$ cells $\left./ \mathrm{mL}\right)$ were suspended in different co-culture media and seeded into T25 cell culture flasks. After incubation at $37^{\circ} \mathrm{C}$ in $5 \% \mathrm{CO}_{2}$ for $48 \mathrm{~h}$, macrophages or osteoblasts were counted. Based on the growth of the different bacterial strains and cells involved (Fig. 1), a co-culture medium consisting of $98 \%$ DMEM-HG-complete with $2 \%$ THB or TSB added, depending on the bacterial strain ( $S$. mitis or $S$. aureus, respectively), was chosen for further experiments and denoted as "modified culture medium". Experiments were done in triplicate with separately grown bacteria and cells.

\section{Bacterial contamination of implant surfaces}

Contamination of implant surfaces was achieved in a parallel plate flow chamber $\left(175 \times 17 \times 0.75 \mathrm{~mm}^{3}\right)$. The bottom plate of the flow chamber consisted of transparent polymethylmethacrylate (PMMA) in which $1 \mathrm{~mm}$ deep inserts were prepared in the centre region of the plate to hold the implant material discs. The PMMA bottom plate was cleaned in a $2 \%$ RBS detergent solution (Omniclean, Breda, the Netherlands) under sonication and thoroughly rinsed in demineralised water, $70 \%$ ethanol, sterile water and finally washed with sterile ultrapure water prior to use. The flow chamber was equipped with heating elements and kept at $37^{\circ} \mathrm{C}$ throughout an experiment. Prior to each experiment, all tubes and the flow chamber were filled with suitable buffer, adhesion buffer for $S$. mitis and PBS for $S$. aureus. After removing all air bubbles from the system, a bacterial suspension in buffer was perfused through the system at a shear rate of $11 \mathrm{~s}^{-1}$. Bacterial adhesion to transparent PMMA was observed at different regions adjacent to each of the implant material discs using a CCD camera (Basler AG, Ahrensburg,
Germany) mounted on a phase-contract microscope Leica DM2000 (Leica Microsystems Ltd., Wetzlar, Germany) with a $40 \times$ objective lens. When the number of bacteria adhering to PMMA amounted to $10^{3} /$ $\mathrm{cm}^{2}$, as directly observed using the phase-contrast microscope, flow was switched to buffer in order to remove non-adhering bacteria from the tubes and chamber. Subsequently, flow was switched to the appropriate culture medium for each bacterial strain for $1 \mathrm{~h}$ growth, and switched to buffer again to remove non-adhering bacteria and further experiments were conducted. In a separate series of experiments, the number of bacteria adhering on PMMA was related to the corresponding number of bacteria adhering to each of the non-transparent dental implant materials involved (Fig. 2). After allowing bacterial adhesion, the chamber was filled with LIVE/DEAD staining solution, containing $3.34 \mathrm{mmol} / \mathrm{L}$ SYTO 9 and $20 \mathrm{mmol} / \mathrm{L}$ propidium iodide (Molecular Probes Inc, USA) in demineralised water and stored for $15 \mathrm{~min}$ in the dark at room temperature. Live and dead bacteria adhering on the transparent PMMA and each of the implant material discs were counted using a fluorescence microscope (Leica DM4000B water objective $40 \times$ ), taking 5 images of each disc. Subsequently, a ratio was calculated that could be used to determine the number of bacteria on the non-transparent implant materials from the number of bacteria adhering on PMMA, according to

$$
\text { Factor }=\frac{(\# \text { bacteria on } \text { disc })}{(\text { \#bacteria on } P M M A)}
$$

Using this ratio, the number of contaminating bacteria adhering on the implant material can be derived without staining from the number of bacteria adhering on PMMA next to a sample disc determined using a phase-contrast microscope. Experiments were done in triplicate with separately grown bacteria.
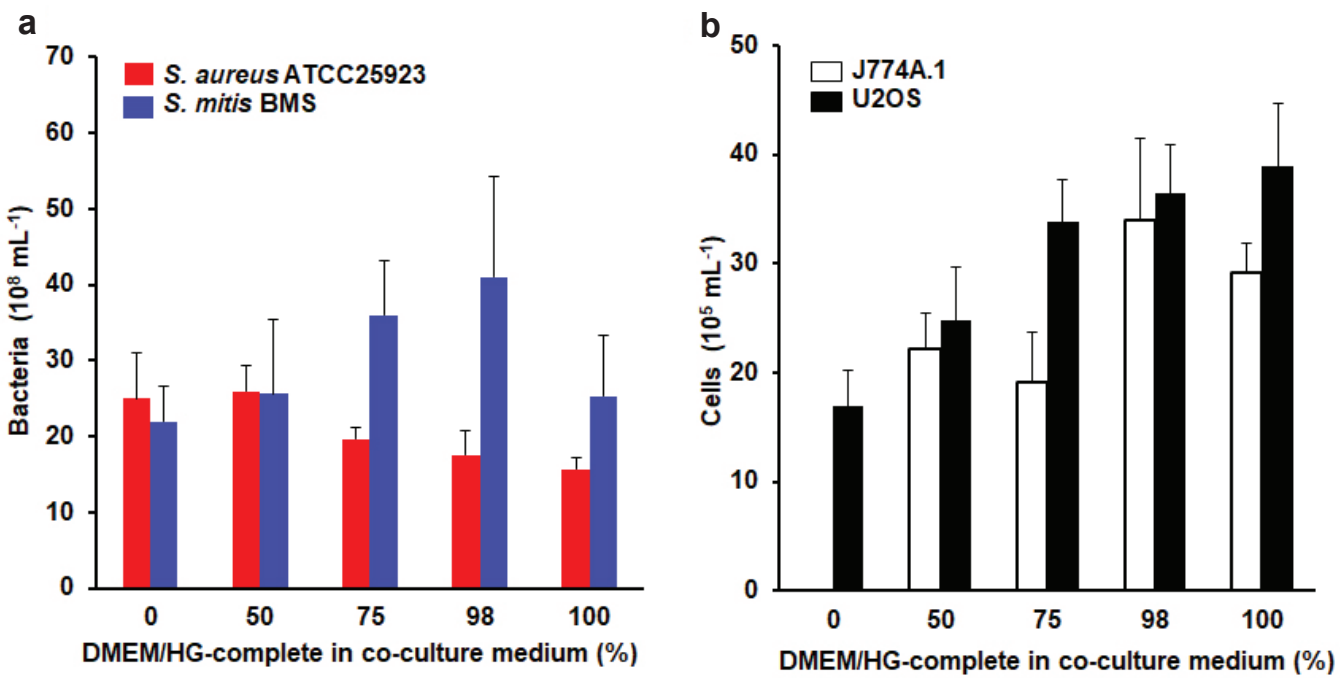

Fig. 1. Modified growth medium for co-culturing. (a) Bacterial numbers after growth for $16 \mathrm{~h}$ as a function of the percentage of DMEM-HG-complete in combination with THB medium for S. mitis or TSB medium for S. aureus. $100 \%$ represents DMEM-HG-complete cell growth medium. (b) Growth of J774A.1 macrophages and U2OS cells as a function of the percentage of DMEM-HG-complete in combination with THB medium. Error bars represent standard deviations over triplicate experiments with separately grown bacteria and cells. 


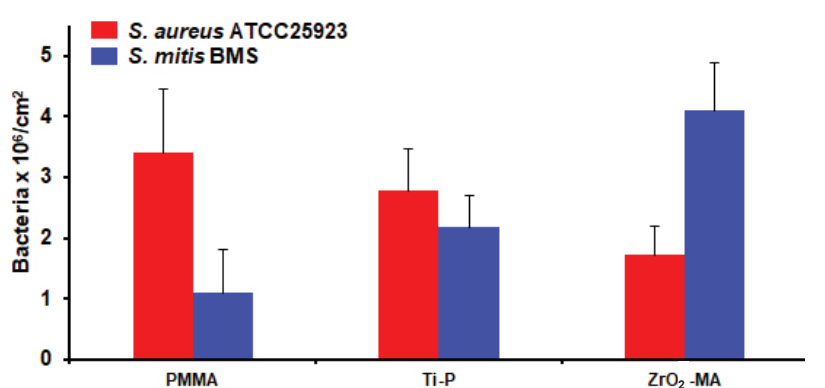

Fig. 2. Bacterial contamination of implant surfaces. Bacterial adhesion to PMMA and the dental implant material discs on the bottom plate of a parallel plate flow chamber, determined using fluorescence microscopy after bacterial LIVE-DEAD staining, required to derive the exact number of contaminating bacteria in absence of staining on the non-transparent implant materials compared to transparent PMMA.

\section{Bacteria and macrophages bi-cultures}

The interaction between bacteria and macrophages was determined in different ways, involving either phagocytosis rates on the dental implant materials or macrophage polarisation.

\section{Phagocytosis rates}

After bacterial contamination of the implant surfaces, flow was switched to modified culture medium with suspended macrophages $\left(6 \times 10^{5}\right)$ $\mathrm{mL})$. When the flow chamber was completely filled with a macrophage suspension, flow was stopped and macrophages were allowed to sediment. After $2 \mathrm{~h}$, the flow chamber was filled with LIVE/DEAD stain to highlight the macrophages and bacteria remaining after phagocytosis for counting using fluorescent microscopy. A phagocytosis rate was calculated from the number of macrophages and the number of contaminating bacteria prior to and after phagocytosis (Da Silva Domingues et al., 2013) according to

$$
P R=\frac{\left(N_{b}, \text { before }-N_{b}, \text { after }\right)}{\left(N_{m} \times N_{b}, \text { before }\right)(\Delta t i m e)}
$$

in which $P R$ is the phagocytosis rate, $N_{b, \text { before }}$ is the number of bacteria/ $\mathrm{cm}^{2}$ contaminating the implant material prior to phagocytosis and $N_{b \text {, after }}$ is the number of bacteria/ $\mathrm{cm}^{2}$ after phagocytosis. $N_{m}$ is the number of macrophages $/ \mathrm{cm}^{2}$. Dtime is the time allowed for phagocytosis, i.e. $2 \mathrm{~h}$. Experiments were done in triplicate with separately grown bacteria and macrophages.

Ym1 secretion to distinguish M1- and M2-phenotypes Phenotypic polarisation of murine macrophages in the direction of pro-inflammatory, fighting M1- or anti-inflammatory, fix-and-repair M2-phenotypes (Bujisic and Martinon, 2017; Mills and Ley, 2014) was studied in the presence and absence of contaminating bacteria on Ti-P and $\mathrm{ZrO}_{2}-\mathrm{MA}$ surfaces. M1- and M2macrophages can be distinguished by the presence of different transmembrane glycoproteins, of which $\mathrm{Ym} 1$ is unique to M2-phenotypic polarisation in murine macrophages (Bujisic and Martinon, 2017; Mills and Ley, 2014). After filling the flow chamber, equipped with a bacterially contaminated sample, with a macrophage suspension in modified culture medium, $48 \mathrm{~h}$ of growth was allowed after which macrophages were fixed with $3.7 \%$ paraformaldehyde (PFA) for $20 \mathrm{~min}$ and stained at room temperature. Fixed macrophages were permeabilised using $0.5 \%$ Triton-X100 in PBS for $3 \mathrm{~min}$, and the nonspecific background was blocked using $5 \%$ bovine serum albumin (BSA) in PBS for $30 \mathrm{~min}$. Fixed macrophages were incubated first with antibody Ym1 [goat-anti-mouse (1\% (v/v) R\&D Systems, Oxon, United Kingdom) in PBS and BSA $(1 \% \mathrm{w} / \mathrm{v})]$ for $60 \mathrm{~min}$ and washed $3 \times$ with $1 \%$ BSA in PBS for $5 \mathrm{~min}$. Subsequently, macrophages were stained with a second antibody $[0.5 \%(\mathrm{v} / \mathrm{v})$ donkey-anti-goat IgG for Ym1-labelled with TRITC, ThermoFisher Scientific, Waltham, USA] and $2 \mu \mathrm{g} /$ $\mathrm{mL}$ phalloidin-FTIC for $60 \mathrm{~min}$ and washed $2 \times$ with $1 \%$ BSA in PBS for 5 min, followed by a final rinse in PBS for $5 \mathrm{~min}$. Macrophages with and without Ym1-expression appear green-fluorescent due to phalloidin-FTIC staining upon excitation at $495 \mathrm{~nm}$. Macrophages expressing Ym1 appear red-fluorescent due to Ym1-antibody labelling upon excitation at 547 nm (Bujisic and Martinon, 2017; Raes et al., 2005; Vasse et al., 2018). For each sample, 5 randomly chosen images were taken. The number of adhering M1- and M2-macrophages per unit area were determined using Scion Image software. Experiments were done in triplicate with separately grown bacteria and macrophages.

\section{IL-10 and IL-12 cytokine expression}

Whereas Ym1 staining is a convenient way to establish whether murine macrophages are in an M1- or M2-phenotype, polarisation usually involves a broad spectrum of polarisation states characterised by expression of different cytokines. Fighting M1- and fix-and-repair M2-phenotypes may be considered as the two extremes of this broad spectrum. Previously, it was established that IL-10 and IL-12 cytokine expression by macrophages is highly dependent on the bacterial strain involved and the bacterial concentration to which macrophages are exposed (Luan et al., 2020). A parallel-plate flow-chamber with bacteria adhering to the bottom plate provides an insufficient number of bacteria to study cytokine surface expression by macrophages and additional experiments were done in 24-well plates, according to an established protocol (Christoffersen et al., 2014) in order to relate Ym1-expression to cytokine expression. Briefly, macrophages ( $1 \mathrm{~mL}, 10^{5}$ cells/ $\mathrm{mL}$ ) were seeded on the dental implant materials in a 24-well plate and cultured in DMEM-HG-complete for $48 \mathrm{~h}$, followed by a $12 \mathrm{~h}$ starvation period in serum-free medium. Subsequently, samples were exposed to different concentrations of bacterial 
suspensions in DMEM-HG-complete medium for $24 \mathrm{~h}$, supplemented with $24 \mathrm{mg} / \mathrm{L}$ gentamicin for $3 \mathrm{~h}$, in order to avoid bacterial growth. After washing with DMEM-HG-complete, fresh medium was added and samples were incubated for another $24 \mathrm{~h}$. After $24 \mathrm{~h}$, the supernatant was collected and stored at $-20^{\circ} \mathrm{C}$ for the enzyme-linked immunosorbent assay (ELISA). A Quantikine mouse IL-10, IL-12 immuno-assay kit (R\&D Systems, Minneapolis, MN, cat. M 1000B and cat. M 1270, respectively), was used according to the manufacturer's instructions. The absorbance of the supernatant was measured at 450/570 nm using a microplate reader (FLUOstar OPTIMA, BMG Labtech, Offenburg, Germany). Experiments were done in triplicate with separately grown bacteria and macrophages.

\section{Osteoblast adhesion and spreading in different mono-, bi- and tri-cultures}

Dental implant materials were placed in a 48 -well plate and $10 \mu \mathrm{L}$ of a bacterial suspension $\left(4 \times 10^{4} / \mathrm{mL}\right)$ in buffer was put on each sample and left for $1 \mathrm{~h}$ at room temperature in order to contaminate the dental implant surfaces with adhering bacteria. After $1 \mathrm{~h}$, samples were dipped $3 \times$ in sterile buffer and placed in a new well. In each well, an implant material disc with or without bacterial contamination a $1 \mathrm{ml}$ of $\mathrm{U} 2 \mathrm{OS}$ cell suspension $\left(2 \times 10^{4} / \mathrm{mL}\right)$ in modified culture medium was added and incubated for $48 \mathrm{~h}$ at $37^{\circ} \mathrm{C}$ in $5 \% \mathrm{CO}_{2}$. After $48 \mathrm{~h}$, the cells were fixed with $3.7 \%$ PFA and stained with Phalloidin-tetramethyl rhodamine isothiocyanate (TRITC)/ 4',6-diamidino-2-phenylindole (DAPI). Images were taken using fluorescence microscopy. The number of adhering cells per unit area and the percentage surface coverage of the U2OS cells were determined using Scion Image software. The ratio of surface coverage to the number of cells directly yields the spread area per individual cell. For each sample 5 randomly chosen images were captured.

For tri-culture experiments, with a bacterially contaminated disc in each well, $1 \mathrm{~mL}$ of mixed cell suspension in modified culture medium was added, $2 \times 10^{4} / \mathrm{mL} \mathrm{U2OS} \mathrm{and} 4 \times 10^{4} / \mathrm{mL} \mathrm{J774A.1} \mathrm{and}$ incubated for $48 \mathrm{~h}$ at $37{ }^{\circ} \mathrm{C}$ in $5 \% \mathrm{CO}_{2}$. After $48 \mathrm{~h}$, samples were fixed with $3.7 \%$ PFA and stained with Phalloidin-TRITC/DAPI. Fluorescence microscopy images were captured. The number of adhering cells per unit area and the percentage surface coverage were determined.

Macrophage polarisation in the relevant cocultures was examined using Ym1-expression, as described above. All experiments were done in triplicate with separately grown bacteria and cells.

\section{Results}

Phagocytosis rates differed significantly between contaminating $S$. aureus and $S$. mitis and between contaminated Ti-P and $\mathrm{ZrO}_{2}-\mathrm{MA}$. Phagocytosis rates of $S$. aureus over a $2 \mathrm{~h}$ time period were significantly $\left(p<0.01\right.$, Student's $t$-test) higher on Ti-P than on $\mathrm{ZrO}_{2}-$ MA, but phagocytosis rates of $S$. mitis were similarly low on both dental implant materials (Fig. 3).

Both in absence and in presence of osteoblasts or bacteria, macrophages in mono-culture did not express Ym1, and all maintained their M1phenotype to fight the presence of the biomaterial, regardless of the implant material involved (Table 2). On bacterially-contaminated implant surfaces, macrophages in bi-cultures did not survive the $48 \mathrm{~h}$ presence of adhering $S$. aureus. In the presence of S. mitis adhering on Ti-P, $99 \%$ of the macrophages displayed Ym1-expression after $48 \mathrm{~h}$, corresponding to the polarisation of nearly all macrophages to the fix-and-repair M2-phenotype, despite the absence of osteoblasts. On $\mathrm{ZrO}_{2}-\mathrm{MA}$, however, polarisation to both Ym1-expressing M2-phenotype and M1phenotype the non Ym1-expressing cells, were observed.

In tri-cultures involving macrophages and osteoblasts on bacterially contaminated implant surfaces, Ym1-expression decreased - indicative of a partial return to their fighting, M1-phenotype although both M1- and M2-phenotypes remained clearly present with more macrophages tending to the M2-phenotype on $\mathrm{ZrO}_{2}-\mathrm{MA}$ than on Ti-P.

In planktonic bi-cultures of bacteria and macrophages, cytokine secretion of IL-10 and IL12 was mostly below detection level (Table 3 ). In bi-culture with $S$. aureus, murine macrophages did not express $\mathrm{Ym} 1$, suggesting $100 \%$ polarisation of macrophages to the fighting, M1-phenotype. Also, in planktonic bi-culture with $S$. mitis, macrophages did not express $Y \mathrm{~m} 1$ and remained polarised in their M1-phenotype up to a streptococcal concentration of $10^{7} / \mathrm{mL}$. Ym1-expression characteristic of the fix-andrepair, M2-phenotype, only appeared at the highest bacterial concentration applied $\left(10^{8} / \mathrm{mL}\right)$ and was accompanied by IL-10 expression. Possibly, this is because the extremely high bacterial concentration was erroneously interpreted by the macrophages to mean that there must be tissue cells present, requiring fixing-and-repair.

U2OS cells nearly fully covered both implant materials (Fig. 4a) in absence of contaminating

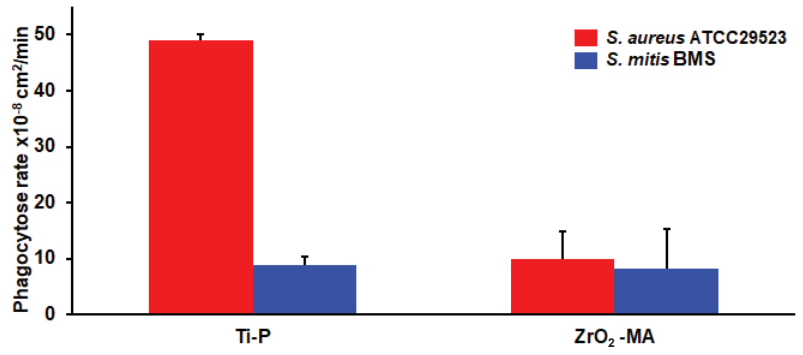

Fig. 3. Phagocytosis rates on PMMA, Ti-P and ZrO2-MA. Phagocytosis rate of $S$. aureus and S. mitis on the 2 dental implant materials involved in this study after $2 \mathrm{~h}$ of phagocytosis. Error bars represent standard deviations over triplicate experiments with separately grown bacteria and macrophages. 
Table 2. Percentages of M1- and M2-phenotype J774A.1 macrophages in mono-, bi- and tri-cultures on Ti-P and $\mathrm{ZrO}_{2}-\mathrm{MA}$ surfaces after $48 \mathrm{~h}$ of growth. Polarisation to M1- and M2-phenotypes were identified based on Ym1-staining, identifying macrophages expressing the Ym1-transmembrane glycoprotein as M2-macrophages. Data represent averages \pm standard deviation over 3 separate cultures of bacteria and macrophages. ${ }^{*}$ fewer than 10 macrophages per image.

\begin{tabular}{|c|c|c|c|c|}
\hline \multirow[b]{2}{*}{ Culture type } & \multicolumn{2}{|c|}{ Ti-P } & \multicolumn{2}{|c|}{$\mathrm{ZrO}_{2}$-MA } \\
\hline & M1 & M2 & M1 & M2 \\
\hline \multicolumn{5}{|c|}{ Macrophages in mono-culture } \\
\hline J774A.1 & $99 \pm 38$ & $1 \pm 1$ & $99 \pm 23$ & $1 \pm 1$ \\
\hline \multicolumn{5}{|c|}{ Macrophages in bi-culture } \\
\hline J774A.1 + U2OS & $99 \pm 19$ & $1 \pm 1$ & $99 \pm 38$ & $1 \pm 1$ \\
\hline $\begin{array}{c}\text { J774A.1 + } \\
\text { S. mitis BMS }\end{array}$ & $1 \pm 2$ & $99 \pm 50$ & $36 \pm 137$ & $64 \pm 121$ \\
\hline $\begin{array}{l}\text { J774A.1 + } \\
\text { S. aureus ATCC25923 }\end{array}$ & Not quantifiable ${ }^{*}$ & Not quantifiable & Not quantifiable & Not quantifiable \\
\hline \multicolumn{5}{|c|}{ Macrophages in tri-culture } \\
\hline $\begin{array}{c}\text { J774A.1 + U2OS + } \\
\text { S. mitis BMS }\end{array}$ & $76 \pm 30$ & $24 \pm 71$ & $59 \pm 47$ & $41 \pm 32$ \\
\hline $\begin{array}{l}\text { J7774A.1 + U2OS + } \\
\text { S. aureus ATCC25923 }\end{array}$ & Not quantifiable* & Not quantifiable & Not quantifiable & Not quantifiable \\
\hline
\end{tabular}

Table 3. Percentages of M1- and M2-phenotypes in planktonic bi-cultures after $48 \mathrm{~h}$ exposure to bacterial suspensions with different bacterial concentration as compared with IL-10 and IL-12 cytokine secretion. M1- and M2-phenotypes were identified based on Ym1-staining, identifying macrophages expressing the Ym1-transmembrane glycoprotein as M2-phenotype. Data represent averages \pm standard deviation over 3 separate cultures of bacteria and macrophages. ${ }^{*}$ Cytokine expression $<30 \mathrm{pg} / \mathrm{mL}$.

\begin{tabular}{|c|c|c|c|c|}
\hline \multirow[b]{2}{*}{ Bacterial concentration $\left(\mathrm{mL}^{-1}\right)$} & \multicolumn{2}{|c|}{ Phenotype of macrophages (\%) } & \multicolumn{2}{|c|}{ Cytokine expression (pg/mL) } \\
\hline & M1 & M2 & IL-10 & IL-12 \\
\hline \multicolumn{5}{|c|}{ S. aureus ATCC25923 } \\
\hline $10^{4}$ & $100 \pm 0$ & $0 \pm 0$ & Below detection* & Below detection \\
\hline $10^{6}$ & $100 \pm 0$ & $0 \pm 0$ & Below detection & Below detection \\
\hline $10^{8}$ & $100 \pm 0$ & $0 \pm 0$ & Below detection & Below detection \\
\hline \multicolumn{5}{|c|}{ S. mitis BMS } \\
\hline $10^{4}$ & $100 \pm 0$ & $0 \pm 0$ & Below detection & Below detection \\
\hline $10^{6}$ & $98 \pm 12$ & $2 \pm 2$ & Below detection & Below detection \\
\hline $10^{8}$ & $3 \pm 22$ & $97 \pm 3$ & 124 & Below detection \\
\hline
\end{tabular}

bacteria, and regardless of the presence of macrophages, although in presence of macrophages this high surface coverage was achieved by fewer U2OS cells than in absence of macrophages (Fig. 4 b). Both cell surface coverage as well as cell number decreased dramatically in the presence of contaminating bacteria. Macrophages provided a clear aid in restoring surface coverage by cells in the case of $S$. mitis contamination of the surfaces. On $S$. mitis contaminated Ti-P, restoration of surface coverage by macrophages ( $p<0.05$, Student $t$-test) was achieved by fewer adhering osteoblasts $(p<0.05$, Student $t$-test). Also on $\mathrm{ZrO}_{2}-\mathrm{MA}$ surfaces, restoration of surface coverage by osteoblasts appeared to be accompanied by a decrease in the number of cells, although not statistically significant, implying a more extensive spreading of individually adhering cells for both materials. Aid provided by macrophages against contaminating $S$. aureus was absent on $\mathrm{ZrO}_{2}$ MA, while the aid observed against S. aureus on Ti-P could not be shown to be statistically significant.

\section{Discussion}

Immune cells have long been recognised for their pivotal role in determining the interplay between tissue cells and invading bacterial pathogens on a biomaterial surface (Thalji et al., 2014), including dental implants. Macrophages direct the outcome of the host immune response against implanted materials and are predominantly found at the tissuematerial interface (Davenport Huyer et al., 2020; Mills and Ley, 2014; Wang et al., 2018). It was demonstrated that phagocytosis, macrophage polarisation and the aid provided by macrophages to tissue cells attempting to cover a surface, depended on the bacterial strain and dental implant material involved.

Phagocytosis rates of contaminating S. aureus adhering to smooth Ti-P, over a $2 \mathrm{~h}$ time period, were significantly higher than on rougher $\mathrm{ZrO}_{2}-$ MA. Phagocytosis rates of adhering S. mitis were similarly low on both materials. This strain-specific difference was probably due to the high virulence 
Fig. 4. Osteoblast spreading in mono-, bi- and tri-cultures on Ti-P and $\mathrm{ZrO}_{2}$ MA. (a) Surface coverage of U2OS on Ti-P and $\mathrm{ZrO}_{2}-\mathrm{MA}$ in absence and presence of macrophages, S. mitis BMS or S. aureus ATCC25923 and either of the two strains and macrophages J774A.1. (b) Same as panel (a), now for the number of U2OS cells per $\mathrm{cm}^{2}$. Error bars represent standard deviations over triplicate experiments with separately grown bacteria and cells.

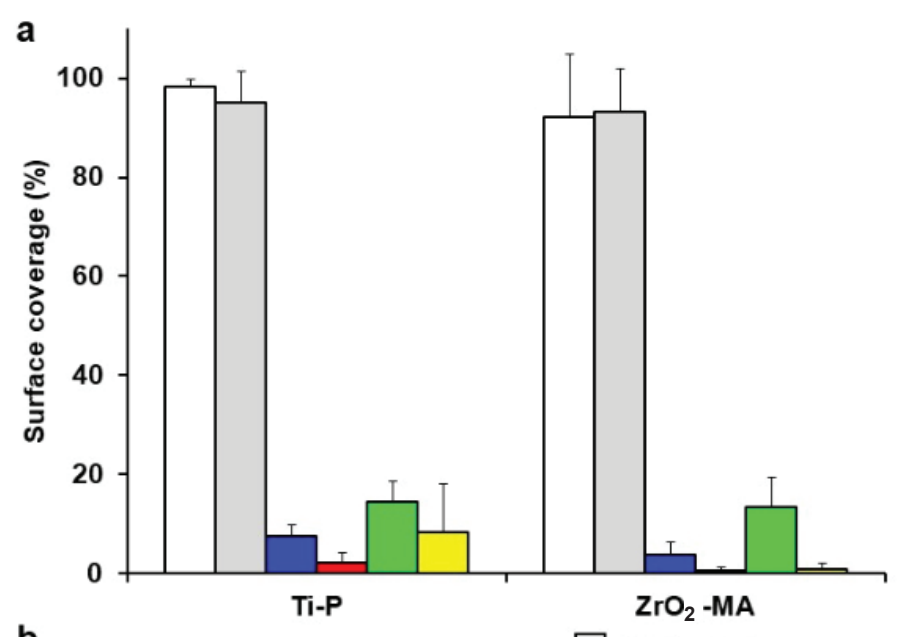

b

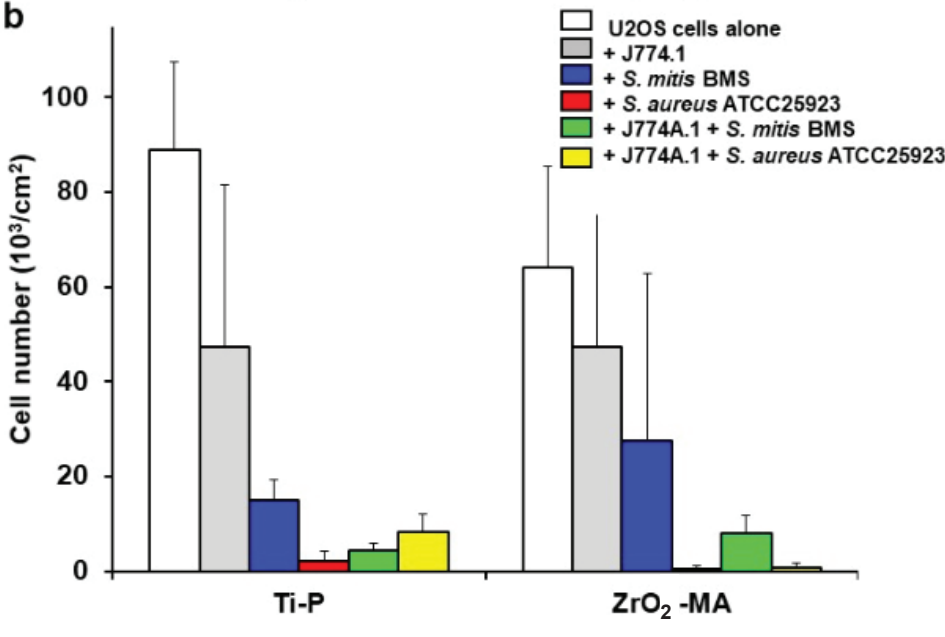

of $S$. aureus compared with $S$. mitis as a chemotactic driving force for macrophage displacement towards an adhering bacterium. S. mitis is a member of the oral microbiome at health (Aas et al., 2005). In coculture studies mimicking the race for the surface, S. aureus invariably wins (Luan et al., 2020). S. aureus can produce potent toxins and antibody-inactivating proteins (Oliveira et al., 2018), often leading to acute, severe and difficult to treat infections (Busscher et al., 2012). Presence of S. aureus at implant sites at 12 weeks after implantation was highly predictive for the occurrence of peri-implantitis (Canullo et al., 2016; Salvi et al., 2008).

Phagocytosis rates of bacteria adhering on a surface have been shown to vary between $5 \times 10^{-8}$ to $16 \times 10^{-8} \mathrm{~cm}^{2} / \mathrm{min}$ on material surfaces with differing charge and hydrophobicity (Da Silva Domingues et al., 2015). Compared to glass, various polymeric biomaterials and stainless steel, Ti-P exhibits an extremely high phagocytosis rate of adhering S. aureus (compare Fig. 3). Phagocytosis rates of S. mitis on the dental implant materials studied were comparable with available literature data. This suggests that the combination of the high virulence of $S$. aureus and a smooth titanium surface is responsible for the high phagocytosis rate, providing a strong chemotactic driving force for macrophage displacement towards contaminating staphylococci, while a smooth surface provides few obstacles to macrophage displacement.
Macrophage polarisation in bi-culture experiments required $48 \mathrm{~h}$ and macrophages had difficulty surviving such a long-term presence of adhering, relatively virulent, $S$. aureus. Macrophages, in absence of contaminating $S$. mitis did not express $\mathrm{Ym} 1$, but in presence of adhering streptococci nearly $100 \%$ polarisation towards the Ym1-expressing, fix-and-repair M2-phenotype occurred. In tricultures, polarisation towards the Ym1-expressing M2-phenotype was less and most of macrophages remained in their fighting, M1-phenotype. Occurrence of the fighting, M1-phenotype was largest in tri-cultures on Ti-P, concurrent with a higher phagocytosis rate and more efficient help towards U2OS cells in maintaining surface coverage than observed on $\mathrm{ZrO}_{2}-\mathrm{MA}$.

The distinction between fighting, M1- and fixand-repair, M2-macrophages encompasses a broad spectrum of phenotypes (Wang et al., 2018) that is not accounted for in the identification of M1- and M2-phenotypes based on Ym1-expression applied in the current study. However, in several routine cytokine-based identification assays (Christofferson et al., 2014; Gries and Kielian, 2017) on macrophage polarisation, the cells are grown on a substratum surface and directly exposed to high numbers of bacteria. This is opposite to the situation on bacterially contaminated surfaces, comprising relatively low numbers of adhering bacteria. 
In line with other planktonic bi-culture studies (Christofferson et al., 2014; Gries and Kielian, 2017) on macrophage polarisation, IL-12 expression remained below detection levels for $S$. aureus and $S$. mitis, as observed by others for Escherichia coli (Christofferson et al., 2014) and Staphylococcus epidermidis (Luan et al., 2020). IL-10 accompanied expression of Ym1 for E. coli (Christofferson et al., 2014) and S. epidermidis (Luan et al., 2020), but only at bacterial concentrations above $10^{7} / \mathrm{mL}$, as also observed in the current study for $S$. mitis. The high bacterial concentration at which Ym1-expression is accompanied by IL-10 expression, has been suggested to indicate that Ym1-expression is a first step in the full polarisation of macrophages towards their M2-phenotype (Luan et al., 2020).

Concurrent with the high phagocytosis rate of $S$. aureus on Ti-P, Ti-P has another important impact on macrophage polarisation. In tri-cultures of macrophages and U2OS cells on $S$. mitis contaminated Ti-P, three-fold more macrophages adopted their fighting, M1-phenotype rather than their fixand-repair, M2-phenotype. The ratio of M1/M2 macrophages in similar tri-cultures on $\mathrm{ZrO}_{2}-\mathrm{MA}$ was much lower.

Combined, these two unique properties of Ti-P influencing macrophage behaviour, i.e. a higher phagocytosis rate and more M1 directed polarisation, may be responsible for the higher surface coverage by U2OS cells on bacterially-contaminated Ti-P, that was absent on $\mathrm{ZrO}_{2}-\mathrm{MA}$.

\section{Conclusions}

Macrophages display higher phagocytosis rates on S. aureus contaminated smooth Ti-P than on rougher, $\mathrm{ZrO}_{2}-\mathrm{MA}$ surfaces. In tri-cultures with tissue cells on $S$. mitis contaminated Ti-P surfaces macrophages adopt a fighting M1-phenotype in higher percentages than on $\mathrm{ZrO}_{2}-\mathrm{MA}$ surfaces. Therefore, macrophages more efficiently provide aid to tissue coverage over bacterial colonisation of Ti-P than $\mathrm{ZrO}_{2}-\mathrm{MA}$ surfaces. These advantages of titanium implants are supported by the few large-scale clinical studies available (Charalampakis et al., 2012). Nevertheless, probably stimulated by their better aesthetic properties, zirconia is more and more advocated as a metal-free alternative to titanium implants and the success rates of zirconia implants after 36 months are comparable to titanium implants (Bormann et al., 2018). However, little is still known about their failure due to infection while longer-term clinical proof with different edentulous morphologies is still required.

\section{Acknowledgements}

This work was financially supported by National Key Research and Development Programme of China (2016YFC1100402), the National Natural
Science Foundation of China (21334004) and UMCG, Groningen, The Netherlands. The materials used in this study were provided free of charge by Institut Straumann AG, Basel, Switzerland under a Materials Transfer Agreement.

\section{Conflict of interest}

HJB is director-owner of SASA BV. The authors declare no potential conflicts of interest with respect to authorship and/or publication of this article. Opinions and assertions contained herein are those of the authors and are not construed as necessarily representing views of the funding organisation or their employer(s).

\section{References}

Aas JA, Paster BJ, Stokes LN, Olsen I, Dewhirst FE (2005) Defining the normal bacterial flora of the oral cavity. J Clin Microbiol 43: 5721-5732.

Bormann KH, Gelrich NC, Kniha H, Weingart D, Gahlert M (2018) A prospective clinical study to evaluate the performance of zirconium dioxide dental implants in single-tooth edentulous area: 3-year follow-up. BMC Oral Health 18: 181. DOI: 10.1186/ s12903-018-0636-x.

Bujisic B, Martinon F (2017) IRE1 gives weight to obesity-associated inflammation. Nat Immunol 18: 479-480.

Busscher HJ, Van der Mei HC, Subbiahdoss G, Jutte PC, Van den Dungen JJAM, Zaat, SAJ, Schultz MJ, Grainger DW (2012) Biomaterial-associated infection: locating the finish line in the race for the surface. Sci Transl Med 4: 153rv10. DOI: 10.1126/ scitranslmed.3004528.

Canullo L, Rossetti PHO, Tallarico M, Oltra DP (2016) Identification of Staphylococcus aureus at the internal and external implant surfaces in individuals with periimplant disease: a cross-sectional study. J Oral Sci Rehabil 2: 8-13.

Charalampakis G, Leonhardt A, Rabe P, Dahlen G (2012) Clinical and microbiological characteristics of peri-implantitis cases: a retrospective multicenter study. Clin Oral Implants Res 23: 1045-1054.

Christoffersen TE, Olsen Hult LT, Kuczkowska K, Moe KM, Skeie S, Lea T, Kleiveland CR (2014) In vitro comparison of the effects of probiotic, commensal and pathogenic strains on macrophage polarization. Probiotics Antimicrob Proteins 6: 1-10.

Davenport Huyer L, Pascual-Gil S, Wang Y, Mandla S, Lee B, Radisic M (2020) Advanced strategies for modulation of the material-macrophage interface. Adv Funct Mater 30: 1909331. DOI: 10.1002/ adfm.201909331

Da Silva Domingues JF, Roest S, Wang Y, Van der Mei HC, Libera M, Van Kooten TG, Busscher, HJ (2015) Macrophage phagocytic activity toward 
adhering staphylococci on cationic and patterned hydrogel coatings versus common biomaterials. Acta Biomater 18: 1-8.

Da Silva Domingues JF, Van der Mei HC, Busscher HJ, Van Kooten TG (2013) Phagocytosis of bacteria adhering to a biomaterial surface in a surface thermodynamic perspective. PLoS One 8: e70046. DOI: 10.1371/journal.pone.0070046.

Gries CM, Kielian T (2017) Staphylococcal biofilms and immune polarization during prosthetic joint infection. J Am Acad Orthop Surg 25 Suppl 1: S20-S24.

Le DH, Goodman SB, Maloney WJ, Huddleston JI (2014) Current modes of failure in TKA: infection, and stiffness predominate. Clin Orthop Relat Res 472: 2197-2200.

Leseigneur C, Le-Bury P, Pizarro-Cerda J, Dussurget O (2020) Emerging evasion mechanisms of macrophage defenses by pathogenic bacteria. Front Cell Infect Microbiol 10: 577559. DOI: 10.3389/ fcimb.2020.577559.

Luan Y, Van der Mei HC, Dijk M, GeertsemaDoornbusch GI, Atema-Smit J, Ren Y, Chen H, Busscher HJ (2020) Polarization of macrophages, cellular adhesion, and spreading on bacterially contaminated gold nanoparticle-coatings in vitro. ACS Biomater Sci Eng 6: 933-945.

Mills CD, Ley KJ (2014) M1 and M2 macrophages the chicken and the egg of immunity. J Innate Immun 6: 716-726.

Miron RJ, Bosshardt DD (2016) OsteoMacs: key players around bone biomaterials. Biomaterials 82: 1-19.

Mombelli A, Décaillet F (2011) The characteristics of biofilms in peri-implant disease. J Clin Periodont 38 Suppl 11: 203-213.

Oliveira D, Borges A, Simoes M (2018) Staphylococcus aureus toxins and their molecular activity in infectious diseases. Toxins (Basel) 10: 252. DOI: 10.3390/toxins10060252.

Porter SL, Coulter SM, Pentlavalli S, Thompson TP, Laverty G (2018) Self-assembling diphenylalanine peptide nanotubes selectively eradicate bacterial biofilm infection. Acta Biomater 77: 96-105.

Raes G, Van den Bergh R, De Baetselier P, Ghassabeh GH, Scotton C, Locati M, Mantovani A, Sozzani S (2005) Arginase-1 and Ym1 are markers for murine, but not human, alternatively myeloid cells. J Immunol 174: 6561-6562.

Salvi GE, Furts MM, Lang NP, Persson GR (2008) One-year bacterial colonization patterns of
Staphylococcus aureus and other bacteria at implants and adjacent teeth. Clin Oral Implants Res 19: 242-248.

Sapru S, Das S, Mandal M, Ghosh AK, Kundu SC (2018) Prospects of nonmulberry silk protein sericinbased nanofibrous matrices for wound healing - in vitro and in vivo investigations. Acta Biomater 78: 137-150.

Sivaraman K, Chopra A, Narayan AI, Balakrishnan D (2018) Is zirconia a viable alternative to titanium for implant? A critical review. J Prosthodont Res 62: 121-133.

Subbiahdoss G, Saldarriaga Fernández IC, Da Silva Domingues JF, Kuijer R, Van der Mei HC, Busscher HJ (2011) In vitro interactions between bacteria, osteoblast-like cells and macrophages in the pathogenesis of biomaterial-associated infections. PLoS One 6: e24827. DOI: 10.1371/journal. pone.0024827.

Subbiahdoss G, Kuijer R, Grijpma DW, Van der Mei HC, Busscher HJ (2009) Microbial biofilm growth vs. tissue integration: "The race for the surface" experimentally studied. Acta Biomater 5: 1399-1404.

Thalji GN, Nares S, Cooper LF (2014) Early molecular assessment of osseointegration in humans. Clin Oral Implants Res 25: 1273-1285.

Vasse GF, Kühn PT, Zhou Q, Bhusari SA, RekerSmit C, Melgert BN, Van Rijn P (2018) Collagen morphology influences macrophage shape and marker expression in vitro. J Immunol Regen Med 1: 13-20.

Wang X, Wang Y, Bosshardt DD, Miron RJ, Zhang Y (2018) The role of macrophage polarization on fibroblast behavior-an in vitro investigation on titanium surfaces. Clin Oral Investig 22: 847-857.

Yue C, Zhao B, Ren Y, Kuijer R, Van der Mei HC, Busscher HJ, Rochford ETJ (2015) The implant infection paradox: why do some succeed when others fail? Eur Cell Mater 29: 303-313.

Zhao B, Van der Mei HC, Subbiahdoss G, De Vries J, Rustema-Abbing M, Kuijer R, Busscher HJ (2014) Soft tissue integration versus early biofilm formation on different dental implant materials. Dent Mater 30: 716-727.

Editor's note: There were no questions from reviewers for this paper, therefore there is no Discussion with Reviewers section. The Scientific Editor responsible for this paper was Thimios Mitsiadis. 